\title{
Hydrogel Synthesis Directed Toward Tissue Engineering: Impact of Reaction Condition on Structural Parameters and Macroscopic Properties of Xerogels
}

\author{
Borivoj Adnadjević and Jelena Jovanović \\ Faculty of Physical Chemistry, Belgrade University, Studentski Trg 12-16, 11001 Belgrade, Serbia \\ Correspondence should be addressed to Jelena Jovanović, jelenaj@ffh.bg.ac.rs
}

Received 1 June 2011; Revised 13 July 2011; Accepted 13 July 2011

Academic Editor: Shanfeng Wang

Copyright ( $\odot 2011$ B. Adnadjević and J. Jovanović. This is an open access article distributed under the Creative Commons Attribution License, which permits unrestricted use, distribution, and reproduction in any medium, provided the original work is properly cited.

\begin{abstract}
The existence of correlation and functional relationships between reaction conditions (concentrations of crosslinker, monomer and initiator, and neutralization degree of monomer), primary structural parameters (crosslinking density of network, average molar mass between crosslinks, and distance between macromolecular chains), and macroscopic properties (equilibrium swelling degree and xerogel density) of the synthesized xerogels which are important for application in tissue engineering is investigated. The structurally different xerogels samples of poly(acrylic acid), poly(methacrylic acid), and poly(acrylic acid- $g$-gelatin) were synthesized by applying different methods of polymerization: crosslinking polymerization, crosslinking polymerization in high concentrated aqueous solution, and crosslinking graft polymerization. The values of primary structural parameters and macroscopic properties were determined for the synthesized xerogels samples. For all of the investigated methods of polymerization, an existence of empirical power function of the dependence of primary structural parameters and macroscopic properties on the reaction conditions was established. The scaling laws between primary structural parameters and macroscopic properties on average molar mass between crosslinks were established. It is shown that scaling exponent is independent from the type of monomer and other reaction conditions within the same polymerization method. The physicochemical model that could be used for xerogel synthesis with predetermined macroscopic properties was suggested.
\end{abstract}

\section{Application of Hydrogels in Tissue Engineering}

Every year, millions of patients suffer the loss or failure of an organ or tissue as a result of accidents or disease. The field of tissue engineering has developed to meet the tremendous need for organs and tissues [1-3].

Hydrogels are commonly defined as three-dimensional networks of hydrophilic polymers, capable of absorbing significant amounts of water (from $20 \mathrm{~g} / \mathrm{g}$ up to $2000 \mathrm{~g} / \mathrm{g}$ of their dry mass) without dissolving or losing their structural integrity $[4,5]$.

They are also called smart, intelligent, stimuli-responsive, or environmental sensitive materials when a rather sharp change can be induced by changes in the environmental conditions, for example, small changes in temperature. Stimuliresponsive hydrogels are described as smart or intelligent when their sol-gel transition occurs at conditions that can be induced in a living body [6].

Due to their characteristic properties (high swellability in water, hydrophilicity, biocompatibility, and intoxicity) and to their abilities to respond to a variety of changes in the surrounding medium $(\mathrm{pH}$, temperature, ionic strength, light intensity, electric and magnetic field, and presence and concentration of some chemicals), hydrogels have been utilized in a wide range of biological, medical, pharmaceutical, and environmental applications. Hydrogels have structural similarity to the macromolecular-based components in the body and are considered biocompatible, and so, they have found numerous applications as biomaterials, both in tissue engineering and in drug delivery $[7,8]$.

Grodzinski [1] provided comprehensive overview of using gels and hydrogels for biomedical and pharmaceutical applications pointing out on some useful reviewers on 
stimuli-responsive polymeric systems, their applications, and modes of activity [9, 10]. Hydrogels have been shown to be very useful for controlling cell adhesion in tissue engineering $[11,12]$ components of extracellular matrix [13] for reconstruction or repair of soft tissues [14, 15], as biosensors [16] and actuators, [17] and for many other biomedical applications $[18,19]$. They have been utilized as scaffold materials for drug and growth factor delivery, engineering tissue replacements, and a variety of other applications.

They can be applied as space filling scaffolds, scaffolds for bioactive molecule delivery or for cell delivery [20]. An extensive review of the applications of hydrogels for scaffolds and ECMs has been published by Varghese and Elisseeff [21]. They indicated that collagen gels provide a good milieu for chondrocytes that enables preservation of their morphology. Application of these gels for bone regeneration was investigated. Their applications are, however, limited by their mechanical weakness.

Tuzlakoglu et al. [22] described the wet spinning technique of the chitosan fibers as a $3 \mathrm{D}$ fiber mesh, as a potential method of production of scaffolds for tissue engineering. In this context, they investigated their mechanical properties, swelling, cytotoxicity, and bioactivity. Their mesh structures were suitable for cell growth. Tuzlakoglu et al. believe that the scaffolds developed by them might be used for bone tissue engineering.

Guo et al. [23] prepared gene-activated porous chitosangelatin matrices (GAMs) for in vitro expression of the transforming growth factor (TFG-b1) for chondrocytes proliferation.

Liu and Chen-Park presented a novel cell-encapsulating hydrogel family based on the interpenetrating polymer network (IPN) of gelatin and dextran bifunctionalized with methacrylate (MA) and aldehyde (AD) (Dex-MA-AD). It was demonstrated that the dextran-based IPN hydrogels not only supported endothelial cells (ECs) adhesion and spreading on the surface, but also allowed encapsulated smooth muscle cells (SMCs) to proliferate and spread in the bulk interior of the hydrogel. Further, these IPN hydrogels have higher dynamic storage moduli than polyethylene glycol-based hydrogels commonly used for smooth muscle cells (SMCs) encapsulation. These IPN hydrogels appear promising as 3D scaffolds for vascular tissue engineering [24]. It is shown that rather than using adhesive peptide, gelatin which has good biodegradability and low level of immunogenicity and cytotoxicity [25] can also be incorporated into dextran hydrogel [26-28].

$\mathrm{Lu}$ et al. [29] investigated the feasibility of tailoring poly(vinyl alcohol)/poly(acrylic acid) interpenetrating polymer networks (PVA/PAA-IPN) as coatings for implantable neural electrodes. They presented a new approach for improving the electrode-neural tissue interface by using hydrogel PVA/PAA-IPN tailored as coatings for poly(dimethylsiloxane)-based neural electrodes. Although PVA is a kind of polyhydroxyl polymer which is not degradable in most physiological situations [30], the PVA-based hydrogels are broadly applied in tissue engineering because of its excellent mechanical strength and good film formation property [31-34]. The crosslinked poly(acrylic acid) (PAA) is a high water absorbing and protein resistive material widely used in medical field $[35,36]$.

Poly $(N$-isopropylacrylamide) (PNIPAAm) is potentially very attractive for tissue engineering applications, as it exhibits phase transition behavior above the lower critical solution temperature (LCST). The LCST of PNIPAAm in water is approximately $32^{\circ} \mathrm{C}$ and can be matched to body temperature by copolymerization [37]. This will result in the formation of a solid cell/polymer construct, as the gel warms to body temperature. The NIPAAm has been copolymerized with acrylic acid, methacrylic acid, or butylmethacrylic acid, depending on the desired final applications [38-40]. Acrylamide derivatives have also been cross-linked with native proteins [41] or oligodeoxyribonucleotides [42] to form temperature responsive gels. In this situation, conventional polymers could potentially be modified to exhibit thermal transition behavior by utilizing a variety of crosslinking molecules that can induce phase separation in response to temperature changes. This mechanism of phase transition may be ideal for delivery of cells, as crosslinking due the temperature change happened upon introduction to the body. The unique temperature-responsive nature of these polymers is leading to a variety of biological applications. These polymers are also being investigated as an injectable delivery vehicle for cartilage and pancreas engineering [38, 43]. However, limitations of these gels are the nondegradable crosslinks, and the vinyl monomers and crosslinking molecules are toxic, carcinogenic, or teratogenic [44]. In an effort to obviate these issues, dextran-grafted PNIPAAm copolymers have been synthesized, and these may modulate degradation in synchronization with temperature [45].

The possibility of applying PAA-based hydrogels crosslinked by macro-di-isocyanates for retarded drug release was investigated [46]. The work presented by Changez et al. lead to the conclusion that it is possible to deliver gentamicin sulphate using IPNs based on PAA and gelatin in a controlled manner. The authors recommended that these devices may have good therapeutic potential for the treatment of local infections like osteomyelitis [47]. A mucoadhesive polymer complex composed of chitosan and PAA loaded with triamcinolone acetonide (TAA) was prepared. It was found that the TAA was released from the chitosan/PAA complex by nonFickian diffusion [48].

The isothermal kinetics of the release of the drug $(E)$ 4-(4-metoxyphenyl)-4-oxo-2-butenoic acid (MEPBA) structurally similar to (E)-4-aryl-(4-oxo-2-butenoic acid) whose antiproliferative activity towards human cervix carcinoma HeLa has been reported [49] from poly(acrylic acid) hydrogel and poly(acrylic-co-methacrylic acid) (PAMA) hydrogels were studied by Adnadjevic et al. [50, 51]. The process of MEPBA release from PAA hydrogel, almost in entire range, can be described with the model of the drug desorption from the active centers with different specific energies.

The delivery system composed of a dual $\mathrm{pH}$-sensitive and thermosensitive smart polymer gel composed of a random terpolymer of $\mathrm{N}$-isopropylacrylamide, butylmethacrylate, and acrylic acid was designed as a new anti-HIV agent [52]. 
In recent years, hydrogels based on poly(acrylic acid) (PAA), poly(methacrylic acid) (PMA), and their copolymers, complexes, IPNs, or grafted networks have often been used as carriers in drug release systems in recent years because of their multifunctional nature, unique properties, and good biocompatibility $[53,54]$.

\section{Biocompatibility of Hydrogels in Tissue Engineering}

The application of polymers and hydrogels in tissue engineering requires them to be biocompatible, nontoxic and nonimflammatory [55].

An absolutely critical parameter for application in tissue engineering is the biocompatibility of hydrogels. Naturally derived polymers in general demonstrate adequate biocompatibility, while synthetic polymers sometimes may produce negative responses from the body. The processes that follow implantation (inflammation, wound healing, and the foreign-body reaction) depend on the chemical structure, physical structure (porosity), and surface microarchitecture of hydrogels. Kopeček and Yang in their comprehensive review [56] presented a summary of systematic study of the biocompatibility of hydrogels based on crosslinked polyHEMA, poly $(N$-substituted methacrylamide)s, poly(Nmonosubstituted acrylamide)s, and poly $(N, N$ disubstituted acrylamide)s and their copolymers with ionogenic comonomers and revealed that all these structures were well tolerated after subcutaneous implantation in rats and pigs. No significant differences were observed with healing-in of hydrogels of different chemical compositions although significant differences were observed for hydrogels with different morphology. Hoffman revealed that hydrogels designed for use as tissue engineering scaffolds may contain pores large enough to accommodate living cells, or they may be designed to dissolve or degrade away, releasing growth factors and creating pores into which living cells may penetrate and proliferate [57]. The biocompatibility of hydrogels with identical chemical structure but differing in porosity using the models hydrogels of HEMA was compared. Hydrogels of HEMA were prepared by crosslinking copolymerization with ethylene dimethacrylate with different water-to-monomer ratio, which resulted in the formation of homogeneous hydrogels, microporous and macroporous spongy hydrogels with interconnecting channels. The implantation of porous hydrogels resulted in fibrous capsule formation. However, in contrast to homogeneous hydrogels, newly formed blood capillaries and an eosinophilically stained exudate penetrated into the implant. The intensity of the response was greater with higher hydrogel porosity [56].

The interactions of cells with hydrogels significantly affects their adhesion as well as migration and differentiation. The adhesion may be cell-type specific and is dependent on the interaction of specific cell receptors with ligands that are a component or adsorbed onto the materials [57].

\section{Design Synthesis of Xerogels for Tissue Engineering}

Hydrogels in tissue engineering must meet a number of design criteria to function appropriately and promote new tissue formation. These criteria include both classical physical parameters (e.g., degradation and mechanics) and mass transport parameters (diffusion requirements) as well as biological performance parameters and biological interaction requirements of each specific application (e.g., cell adhesion). For example, scaffolds designed to encapsulate cells must be capable of being gelled without damaging the cells, must be nontoxic to the cells and the surrounding tissue after gelling, must allow appropriate diffusion of nutrients and metabolites to and from the encapsulated cells and surrounding tissue, and require sufficient mechanical integrity and strength to withstand manipulations associated with implantation and in vivo existence [58].

For a rational design of biomaterials, all variables influencing cell function and tissue morphogenesis have to be considered. Brandl et al. give comprehensive review which promote a rational design of hydrogels for tissue engineering application with a special emphasizes on their physical properties. Adjusting these parameters to the requirements of each specific application would allow for the creation of "custom-made" biomaterials that direct the development of desired tissues. In the review of Brandl et al., the basic principles of cellular mechanosensitivity, highlighting the problems of characterizing the mechanical properties of biological tissues and hydrogels, are summarized and followed by a discussion on the rational design of hydrogels for tissue-engineering applications, while the impact of mechanical characteristics and degradability on cell function and tissue morphogenesis was pointed out [59].

The areas of active research in tissue engineering include biomaterials design-incorporation of the appropriate chemical, physical, and mechanical/structural properties to guide cell and tissue organization, cell and scaffold integrationinclusion into the biomaterial scaffold of either cells for transplantation or biomolecules to attract cells, including stem cells, from the host to promote integration with the tissue after implantation, and biomolecule delivery inclusion of growth factors and/or small molecules or peptides that promote cell survival and tissue regeneration. The review of Shoichet emphasizes polymers used in medicine and specifically those designed as scaffolds for use in tissue engineering and regenerative medicine and particularly polymer scaffolds used for delivery of cells and biomolecules. The challenges and solutions pursued in designing polymeric biomaterial scaffolds with the appropriate 3 -dimensional structure have been explored [60].

The results of the rapid development of advanced materials science are processing of materials with predicted functional physical, technological, and exploitation characteristics. However, progress in the field of synthesis of needed materials is considerably slow due to the lack of effective methods that can define new technologies with minimal research. 
The predictions of the materials properties, firstly have been based on the association principle in order to be further replaced by the principle of correlation when quantity of information about materials enhanced. The findings of various correlation relationships type property-property and property-composition lead to the development of its significance. Finally, the correlation method reaches its ultimate expression in the so called multivariation analyses which enable discovering limited number of parameters which can be used for defining physicochemical properties of material. Principal limitations specific for the multivariation analyses used for predicting the properties of materials reveal that the structure of material was the crucial point in the process of predicting properties of materials.

In accordance with that, creation of material with predictable properties can be assumed that is solved if the triad technology-structure- property (T-S-P) is known, that is, if functional relationship type: property-structure and structure-technology are established and in that relations, structure has a role of parameter which express relationship: technology-property.

On this manner, prediction of the materials properties, that is, production of materials of predictable properties riches qualitatively new, higher level.

Bearing that in mind, this paper summarizes the effects of reaction conditions (concentrations of crosslinker (Cc), monomer $(\mathrm{Cm})$, and initiator $(\mathrm{Ci})$ and neutralization degree of monomer (ND) on primary structural properties of xerogels (average molar mass between crosslinks $\left(M_{c}\right)$, crosslinking density of network $\left(\rho_{c}\right)$ distance between macromolecular chains $(d)$ and xerogels macroscopic properties (xerogel density $\left(\rho_{x}\right)$, and equilibrium swelling degree $\left(\mathrm{SD}_{\mathrm{eq}}\right)$ for different processes of xerogels/hydrogels synthesis (crosslinking polymerization (CLP), high concentrated aqueous solution crosslinking polymerization (CCLP), and crosslinking graft polymerization (CLGP)) with the aim to elucidate triad T-S$\mathrm{P}$ as presented in Figure 1.

\section{Design of Poly(Acrylic Acid) Xerogel Synthesis via High Concentrated Aqueous Solution Crosslinking Polymerization}

4.1. Synthesis of Poly(Acrylic Acid) Hydrogels. Poly(acrylic acid) (PAA) hydrogels with different concentrations of crosslinker and initiator in reaction mixture were synthesized via high concentrated aqueous solution crosslinking polymerization (CCLP).

For the synthesis, the following materials were used. The monomer, acrylic acid (99.5\%) (AA), was purchased from Merck KGaA, Darmstadt Germany, stored in a refrigerator, and melted at room temperature before use. The crosslinker $\mathrm{N}, \mathrm{N}^{\prime}$-methylene bisacrylamide (MBA) (p.a) was supplied by Aldrich Chemical Co., Milwaukee, USA. The initiator, ammonium peroxodisulphate (p.a) (APS), was purchased from BDH Prolab, USA. Sodium hydroxide (p.a) was obtained from Aldrich Chemical Co., Milwaukee, USA.

The general procedure was as follows. Firstly, $10 \mathrm{~mL}$ of cooled acrylic acid in ice bath to $5^{\circ} \mathrm{C}$ was neutralized

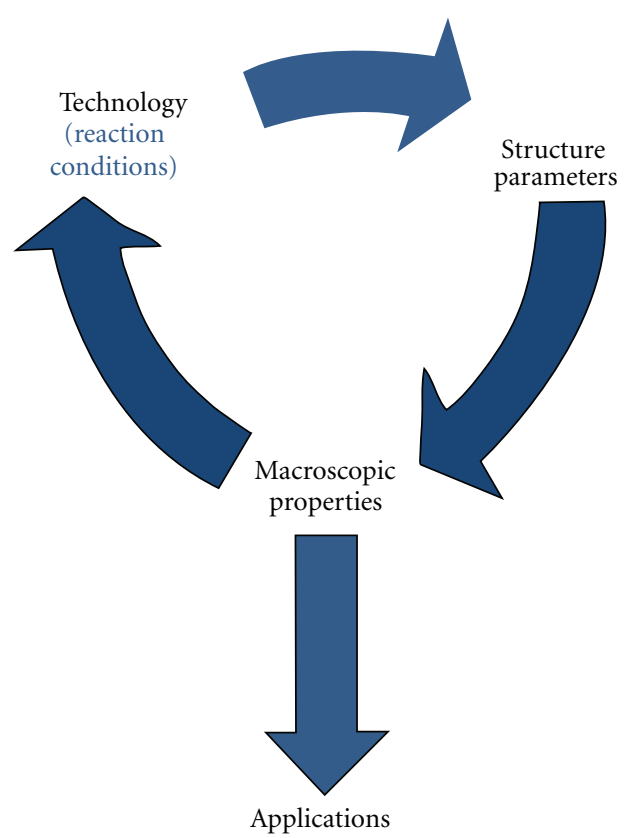

FIgURE 1: Triad technology-structure-property.

to required degree of neutralization by dropwise adding necessary amount of potassium hydroxide aqueous solution (50 wt $\%$ ) under constant stirring. Then, crosslinker aqueous solution $(0.1 \mathrm{wt} \%)$ was added and was stirred approximately $5 \mathrm{~min}$ at ambient temperature. Then, the initiator solution (10 wt $\%$ APS) was added to the reaction mixture. The reaction mixture was once again rapidly stirred, and immediately, the prepared reaction mixture was poured into teflon mold and placed in an thermostat oven at $70^{\circ} \mathrm{C}$ for 0.5 hours.

The resulting products were taken out the teflon mold and sliced into small pieces which were subsequently immersed in excess distilled water. The water was changed every 2-3 hours except overnights for 7 days in order to remove the sol fraction of polymer and unreacted monomer. Subsequently, the washed-out hydrogel was dried in air oven at $100^{\circ} \mathrm{C}$ approximately $8 \mathrm{~h}$ until constant mass was attained. The obtained products were stored in a vacuum exicator until use.

\subsection{Structural Characterization of the Synthesized Poly(Acrylic Acid) Xerogels}

4.2.1. Macroscopic Properties of Xerogels. Macroscopic properties (MP) of xerogels (equilibrium swelling degree $\left(\mathrm{SD}_{\mathrm{eq}}\right)$ and xerogel density $\left(\rho_{\mathrm{xg}}\right)$ ) were determined using the following procedures.

Determination of the Equilibrium Swelling Degree. Dry hydrogel (xerogel) disks with an average weight of $0.10 \mathrm{~g}$ $( \pm 10 \%)$ were left to swell in distilled water in excess distilled water at ambient temperature. The swollen hydrogels samples were taken out from water, wiped to remove excess surface water, and weighted. This was done until the hydrogels attained constant mass, that is, until equilibrium was reached $\left(m_{\mathrm{eq}}\right)$. The equilibrium swelling degree $\left(\mathrm{SD}_{\mathrm{eq}}\right)$ 
defined as the difference between the weight of the swollen hydrogel sample at equilibrium swollen state, that is, when the hydrogel sample attained constant mass $\left(m_{\mathrm{eq}}\right)$, and the weight of the xerogel (dry hydrogel) $\left(m_{0}\right)$ divided by the weight of the xerogel sample $\left(m_{0}\right)$ was determined as a function of time at constant temperature and calculated using:

$$
\mathrm{SD}=\frac{m_{\mathrm{eq}}-m_{0}}{m_{0}} .
$$

For each sample, at least three swelling measurements were performed, and the mean values were used.

The xerogel densities of the synthesized samples were determined by the pycnometer method, using:

$$
\rho_{\mathrm{xg}}=\frac{m_{\mathrm{xg}} \rho_{T}}{m_{1}+m_{\mathrm{xg}}-m_{2}},
$$

where $m_{\mathrm{xg}}$ is the weight of the xerogel sample, $m_{1}$ is the weight of pycnometer filled with toluene, used as the nonsolvent, $m_{2}$ is the weight of pycnometer filled with toluene with the xerogel sample in it, and $\rho_{T}$ is the density of toluene $\left(\rho_{T}=0.864 \mathrm{~g} / \mathrm{cm}^{3}\right)$.

4.2.2. Primary Structural Parameters of the Synthesized Poly (Acrylic Acid) Hydrogels. The primary structural parameters (PSP) of the synthesized poly(acrylic acid) xerogels: average molar mass between the network crosslinks $\left(M_{c}\right)$, crosslinking degree $\left(\rho_{c}\right)$, and the distance between the macromolecular chains $(d)$ were calculated by application of Flory and Rehner Equation [61]

$$
M_{c}=\frac{-\rho_{\mathrm{xg}} V_{\mathrm{H}_{2} \mathrm{O}} v_{2, s}^{1 / 3}}{\ln \left(1-v_{2, s}\right)+v_{2, s}+\chi v_{2, s}^{2}},
$$

where $V_{\mathrm{H}_{2} \mathrm{O}}$ is the molar volume of $\mathrm{H}_{2} \mathrm{O}, v_{2, s}$ is the polymer volume fraction in the equilibrium swollen state, and $\chi$ is the Flory-Huggins interaction parameter between a solvent $\left(\mathrm{H}_{2} \mathrm{O}\right)$ and a polymer (PMAA). The values of $v_{2, s}$ and $\chi$ were calculated using the following expressions:

$$
\begin{gathered}
v_{2, s}=\frac{1}{1+\rho_{\mathrm{xg}} \mathrm{SD}_{\mathrm{eq}}}, \\
\chi=\frac{\ln \left(1-v_{2, s}\right)+v_{2, s}}{v_{2, s}^{2}} .
\end{gathered}
$$

The degree of crosslinking was calculated as

$$
\rho_{c}=\frac{\rho_{x}}{M_{c}}
$$

where $M_{0}$ is the molar mass of the repeating unit.

The distance between the macromolecular chains was calculated as

$$
d=l v_{2, s}^{-1 / 3}\left(2 C_{n} \frac{M_{c}}{M_{0}}\right)^{1 / 2},
$$

where $C_{n}$ is the Flory characteristic ratio $\left(C_{n}(\mathrm{AA})=6.7 \AA\right.$, $\left(C_{n}(\mathrm{MAA})=14.6 \AA\right)$ and $l$ is the carbon-carbon bond length (1.54 $\AA$ ) [62].

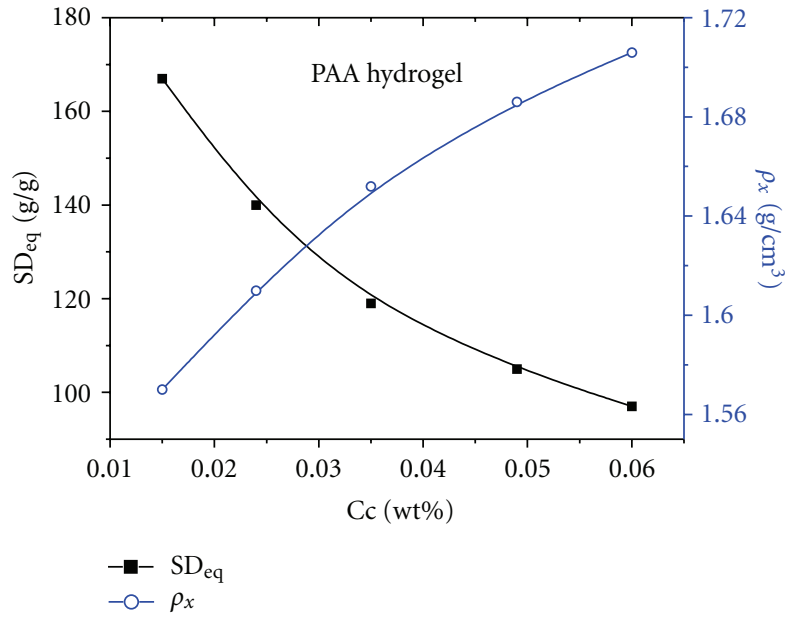

Figure 2: The effect of $\mathrm{Cc}$ on macroscopic properties of the synthesized PAA xerogels.

TABLE 1: Effect of changes in Cc on primary structural parameters of PAA xerogels.

\begin{tabular}{lcccc}
\hline $\mathrm{Cc}, \mathrm{wt} \%$ & $M_{c} \cdot 10^{-5}, \mathrm{~g} / \mathrm{mol}$ & $\rho_{c}, \mathrm{~mol} / \mathrm{m}^{3}$ & $d, \mathrm{~nm}$ & $\chi$ \\
\hline 0.015 & 3.13 & 5.083 & 239 & -0.499 \\
0.024 & 2.51 & 6.506 & 203 & -0.497 \\
0.035 & 1.95 & 8.472 & 170 & -0.503 \\
0.049 & 1.66 & 10.149 & 152 & -0.503 \\
0.060 & 1.51 & 11.261 & 142 & -0.502 \\
\hline
\end{tabular}

4.3. Effects of Crosslinker Concentration on MP and PSP of PAA Xerogel. The samples of PAA hydrogels were synthesized by using reaction mixtures with variable crosslinker concentration within the range $0.015-0.06 \mathrm{wt} \%$ and keeping constant all the others reaction conditions $(\mathrm{Cm}=72 \mathrm{wt} \%, \mathrm{Ci}=$ $0.07 \mathrm{wt} \%, \mathrm{ND}=75 \%, T=70^{\circ} \mathrm{C}$, and $t=30 \mathrm{~min}$ ) with the aim to evaluate the effects of changing $\mathrm{Cc}$ on the values of primary structural parameters and macroscopic properties of the synthesized xerogels.

Figure 2 presents the changes of MP of the synthesized PAA xerogels with the variation in the $\mathrm{Cc}$ in reaction mixture.

Table 1 presents the changes of PSP of the synthesized xerogels with the variation in the $\mathrm{Cc}$ in reaction mixture.

From the results presented in Figure 2 and Table 1, we can conclude that the increasing Cc leads to the increasing values of xerogel density and crosslinking density of xerogel and to the decreasing values of equilibrium swelling degrees, average molar mass between crosslinks, and the distance between the macromolecular chains, while the value of Flory-Huggins interaction parameter between solvent and polymer remains practically unaffected.

An analyses of the established changes of the primary structural parameters and macroscopic properties of synthesized xerogels caused with the variation in crosslinker concentration in reaction mixture revealed an existence of functional $(R \geq 0.99)$ and correlation relationships $(R \leq 0.99)$ 
between them. The found relationship are presented by following empirical Equation (7):

$$
\begin{aligned}
\mathrm{SD}_{\mathrm{eq}} & =32.5 \cdot C_{c}^{-0.40} \quad R=0.99, \\
\rho_{x} & =2.02 \cdot C_{c}^{0.06} \quad R=0.99, \\
M_{c} & =3.3 \cdot 10^{4} \cdot C_{c}^{-0.5} \quad R=0.99, \\
\rho_{c} & =60 \cdot C_{c}^{0.59} \quad R=0.99, \\
d & =47 \cdot C_{c}^{-0.39} \quad R=0.99,
\end{aligned}
$$

where $R$ is correlation coefficient. The data were analyzed using the commercial program Origin Microcal 8.0 and relations with the best correlation coefficient $(R)$ are presented.

Based on above empirical Equation (7), it is easy to conclude that primary structural parameters and macroscopic properties of xerogels $(Y)$ are power functions of concentration of crosslinker in reaction mixture $(X)(8)$

$$
Y=a \cdot X^{b},
$$

where $a$ is prefactor and $b$ is exponent.

Assuming that equilibrium swelling degree is in functional relationship with the primary structural parameters of xerogel, an existence of dependence between $\mathrm{SD}_{\mathrm{eq}}$ and primary structural parameters was investigated. The found relationship are presented by empirical Equation (9).

$$
\begin{array}{cl}
\mathrm{SD}_{\mathrm{eq}}=0.015 \cdot M_{c}^{0.74} & R=0.99, \\
\mathrm{SD}_{\mathrm{eq}}=498 \cdot \rho_{c}^{-0.67} & R=0.94, \\
\mathrm{SD}_{\mathrm{eq}}=0.63 \cdot d^{1.02} & R=0.99 .
\end{array}
$$

The dependences of equilibrium swelling degree on primary structural parameters of xerogel are also power function with different values of prefactor and exponent for different structural parameters. The established power law dependences of equilibrium swelling degree on different primary structural parameters of xerogel confirm the validity of the previously given propose about existing functional relationship between them. The obtained different values of prefactor and exponent for different structural parameters of xerogels point out on dependence of equilibrium swelling degree on structural details of xerogel.

We proposed that the basic structural detail of xerogel is average molar mass of polymer chain between crosslinking points $\left(M_{c}\right)$, and so, the dependences of primary structural parameters $\left(\rho_{c}\right.$ and $\left.d\right)$ and macroscopic property $\rho_{x}$ of xerogel on $M_{c}$ were investigated and obtained dependences are given by empirical Equation (10)

$$
\begin{array}{cl}
\rho_{x}=4.95 \cdot M_{c}^{-0.10} & R=0.98 \\
\rho_{c}=5.44 \cdot M_{c}^{-1.1} & R=0.99 \\
d=0.02 \cdot M_{c}^{0.73} & R=0.99
\end{array}
$$

As we can see, the MP and PSP may be scaled with $M_{c}$ through scaling laws. This confirms the previous assumption

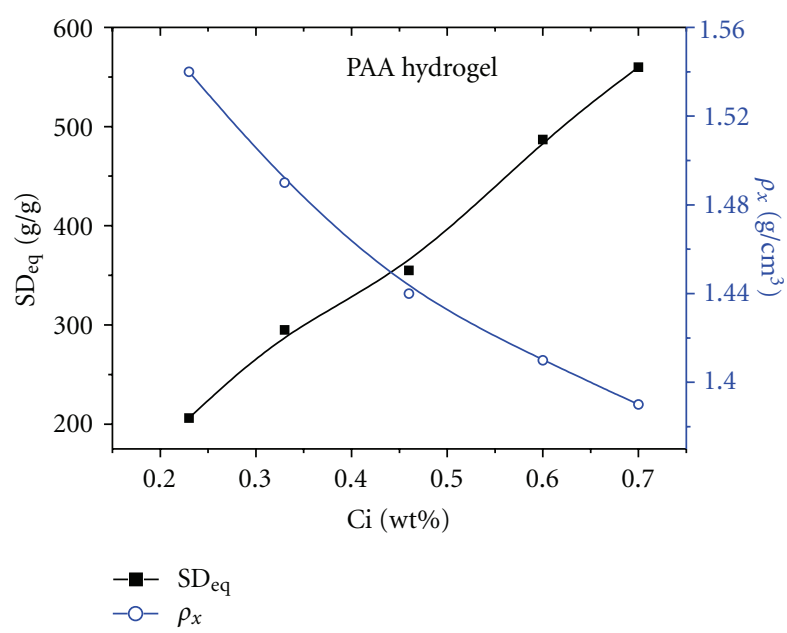

Figure 3: Effect of Ci on $\mathrm{SD}_{\mathrm{eq}}$ and $\rho_{x}$ of PAA xerogels.

TABLE 2: Effect of changes in Ci on primary structural parameters of PAA xerogel.

\begin{tabular}{lcccc}
\hline $\mathrm{Ci}, \mathrm{wt} \%$ & $M_{c} \cdot 10^{-5}, \mathrm{~g} / \mathrm{mol}$ & $\rho_{c}, \mathrm{~mol} / \mathrm{m}^{3}$ & $d, \mathrm{~nm}$ & $\chi$ \\
\hline 0.23 & 3.96 & 3.85 & 284 & -0.50 \\
0.33 & 7.08 & 2.11 & 425 & -0.48 \\
0.46 & 8.64 & 1.70 & 496 & -0.51 \\
0.60 & 13.1 & 1.08 & 671 & -0.52 \\
0.70 & 16.7 & 0.82 & 794 & -0.48 \\
\hline
\end{tabular}

that the basic structural detail of xerogel structure which further determine other primary structural parameters and macroscopic properties of xerogel is average molar mass of polymer chain between crosslinks and implies on law by which macromolecules scaling their PSP.

4.4. Effects of Initiator Concentration on MP and PSP of PAA Xerogel. PAA hydrogels with different concentrations of initiator (from $0.23 \mathrm{wt} \%$ to $0.70 \mathrm{wt} \%$ ) were prepared, while other reaction parameters were kept constant $(\mathrm{Cm}=72 \mathrm{wt} \%$, $\left.\mathrm{ND}=75 \%, \mathrm{Cc}=0.015 \mathrm{wt} \%, T=70^{\circ} \mathrm{C}, t=30 \mathrm{~min}\right)$.

The effects of concentration of initiator in reaction mixture on macroscopic properties of synthesized xerogels are presented in Figure 3.

The effects of concentration of initiator in reaction mixture on primary structural parameters of synthesized xerogels are presented in Table 2.

The increase in the initiator concentration leads to the increase in the equilibrium swelling degree, average molar mass of polymer chain between crosslinks, and distance between the macromolecular chains, while the values of xerogel density and crosslinking density of xerogel decrease. On the contrary to these effects, the value of FloryHuggins interaction parameter between solvent and polymer is practically unaffected with the changes in the initiator concentration.

Like in the case of effects of crosslinker concentration, the changes of primary structural parameters and macroscopic 
properties are in functional and correlation relationships with the concentration of initiator in the reaction mixture, as presented by

$$
\begin{aligned}
\mathrm{SD}_{\mathrm{eq}} & =750 \cdot C_{i}^{-0.87} \quad R=0.98, \\
\rho_{x} & =1.35 \cdot C_{i}^{-0.09} \quad R=0.97 \\
M_{c} & =2.5 \cdot 10^{6} \cdot C_{i}^{1.23} \quad R=0.99, \\
\rho_{c} & =0.54 \cdot C_{i}^{-1.32} \quad R=0.99 \\
d & =1053 \cdot C_{i}^{0.89} \quad R=0.99 .
\end{aligned}
$$

The values of MP and PSP are power functions of the initiator concentration in reaction mixture, with different prefactors and exponents.

Starting from the point that the basic structural detail of xerogel is average molar mass of polymer chain between crosslinking points, as in the case when the effect of Cc evaluated, we again found relationship between the primary structural parameters and properties of xerogel and $M_{c}$ in the form of scaling law, as can be seen from the following empirical equations:

$$
\begin{array}{cc}
\mathrm{SD}_{\mathrm{eq}}=0.02 \cdot M_{c}^{0.71} & R=0.99 \\
\rho_{x}=3.85 \cdot M_{c}^{-0.07} & R=0.97 \\
\rho_{\mathrm{c}}=3.83 \cdot M_{c}^{-1.07} & R=0.99 \\
d=0.03 \cdot M_{c}^{0.72} & R=0.99 .
\end{array}
$$

The established changes of average molar mass of polymer chain between crosslinks with the increasing concentration of initiator are in disagreement with the predictable values of the results which would be obtained by calculation based on the model of kinetics of radical polymerization [63]. In fact, according to that model, the increase in the initiator concentration should lead to the decrease in the average distance of kinetically chains, and therefore, also the average molar mass of polymer chain between crosslinks would decrease.

The found increase in the molar mass of polymer chain between crosslinks in the case of crosslinking polymerization of acrylic acid is in agreement with the theoretically presumption of kinetics model of CLP suggested by Tobita and Hamielec [64], Dusek [65], and Elliott and Bowman [66]. In accordance with them, the increasing initiator concentration in reaction mixture in the course of crosslinking polymerization favors an intramolecular cyclization process over the crosslinking process which leads to the increase in $M_{c}$ of the formed polymer network. Further, the increase in $M_{c}$ causes decrease in the network's crosslink density and increase in the distance between the macromolecular chains and so the equilibrium swelling degree increases.

Therefore, it is possible to completely define technology for preparation xerogels with predetermined macroscopic properties (synthesis design) if the equations listed below are known:

$$
\begin{aligned}
& \mathrm{MP}_{j}=\alpha \cdot M_{c}^{\beta}, \\
& \mathrm{RC}_{i}=\alpha \cdot M_{c}^{\beta 1},
\end{aligned}
$$

where $\mathrm{MP}_{j}$ are the macroscopic properties of the xerogel (equilibrium swelling degree and xerogel density), RC are reaction condition, $\alpha$ and $\alpha_{1}$ are the prefactors, and $\beta$ and $\beta_{1}$ are the exponents.

In that case, the choose of reaction conditions aimed at preparing xerogel with desired macroscopic properties is based on the calculation of the values of molar mass between crosslinks $\left(M_{c}\right)$ according to

$$
M_{c}=\left(\frac{\mathrm{MP}_{j}}{\alpha}\right)^{1 / \beta},
$$

and then, the reaction conditions under which will be synthesized xerogel with predefined value of $M_{c}$ can be calculated by using

$$
\mathrm{RC}_{i}=\left(\frac{M_{c}}{\alpha_{1}}\right)^{1 / \beta_{1}}
$$

\section{Design of Poly(Methacrylic Acid) Xerogel Synthesis via Crosslinking Polymerization}

5.1. Synthesis of Poly(Methacrylic Acid) Hydrogels. Poly (methacrylic acid) hydrogels (PMA) with different concentrations of crosslinker and monomer in reaction mixture were prepared via crosslinking polymerization (CLP) in aqueous media using the modified procedure for poly(acrylic acid) hydrogel synthesis [67].

The general procedure was as follows. Firstly, methacrylic acid (99.5\%) (MA) (purchased from Merck KGaA) (20 wt\% aqueous solution) was neutralized to the required neutralization degree with $25 \mathrm{wt} \%$ sodium hydroxide solution (Sodium hydroxide (p.a) obtained from Aldrich Chemical Co., Milwaukee, USA) under the nitrogen atmosphere and with constant stirring. Then, crosslinker (MBA) aqueous solution $(1 \mathrm{wt} \%)$ was added under stirring and nitrogen bubbling through the mixture for half an hour. Then, the initiator (2,2' -Azobis-[2-(2-imidazolin-2-yl)propane] Dihydrochloride (VA-044) (99.8\%) supplied by Wako Pure Chemical Industries, Ltd. (VA-044)) was added (1 wt\% solution of) and the reaction mixture was once again rapidly stirred and bubbled with nitrogen for a further $20 \mathrm{~min}$. Immediately, the prepared reaction mixture was poured into glass moulds (plates separated by a rubber gasket $2 \mathrm{~mm}$ thick) and placed in an oven at $80^{\circ} \mathrm{C}$, for $3 \mathrm{~h}$.

After the completion the reaction, the resulting products were handled in the same way as the PAA hydrogel. The primary structural parameters and macroscopic properties were determined using the methods given for the PAA xerogels. 
5.2. Effects of Crosslinker Concentration MP and PSP of PMA Xerogel. The samples of PMA hydrogels were synthesized by using reaction mixtures with different crosslinker concentration $(\mathrm{Cc})$ within the range from $0.003 \mathrm{wt} \%$ to $0.006 \mathrm{wt} \%$, while the other reaction conditions were kept constant $\left(\mathrm{Cm}=20 \mathrm{wt} \%, \mathrm{Ci}=0.2 \mathrm{wt} \%, \mathrm{ND}=40 \%, T=80^{\circ} \mathrm{C}\right.$, and $t=3 \mathrm{~h}$ ). The effect of crosslinker concentration on the macroscopic properties of PMA xerogels are presented in Figure 4.

The effects of Cc on primary structural parameters of PMA xerogels are given in Table 3.

It is clear that the increase in crosslinker concentration in reaction mixture results in the increase in the values of xerogel density and crosslinking density of xerogel, while the values of equilibrium swelling degrees, average molar mass between crosslinks, and the distance between the macromolecular chains decrease.

The evaluated changes of primary structural parameters and macroscopic properties of PMMA xerogels are in correlation relationships with the crosslinker concentration in the reaction mixture, which are presented by the empirical Equation (16)

$$
\begin{aligned}
\mathrm{SD}_{\mathrm{eq}} & =0.152 \cdot C_{c}^{-1.26} \quad R=0.98, \\
\rho_{x} & =4.05 \cdot C_{c}^{0.20} \quad R=0.99, \\
M_{\mathrm{c}} & =33.44 \cdot C_{c}^{-1.56} \quad R=0.97, \\
\rho_{c} & =2.83 \cdot C_{c}^{1.57} \quad R=0.97, \\
d & =0.42 \cdot C_{c}^{-1.14} \quad R=0.97 .
\end{aligned}
$$

As in the case of PAA xerogels, the relationships between average molar mass between crosslinks and each particular value of primary structural parameters and macroscopic properties of PMA xerogels are given in the form of scaling law (see (17))

$$
\begin{array}{cc}
\mathrm{SD}_{\mathrm{eq}}=0.01 \cdot M_{c}^{0.79} & R=0.99 \\
\rho_{x}=5.6 \cdot M_{c}^{-0.12} & R=0.97 \\
\rho_{c}=100 \cdot M_{c}^{-1.0} & R=0.99 \\
d=0.03 \cdot M_{c}^{0.73} & R=0.99
\end{array}
$$

The changes in the values of MP and PSP with the increasing $\mathrm{Cc}$ in the reaction mixture may be attributed to the increased degree of crosslinking of polymer chains which is caused with the increased concentration of crosslinker in reaction mixture. As the network's crosslinking density increases, the space between polymer chains decreases as well as the $M_{c}$, and therefore, network rigidity and density of xerogel increases, while the $\mathrm{SD}_{\mathrm{eq}}$ decreases.

5.3. Effects of Monomer Concentration on MP and PSP of $P M A$ Xerogel. In order to examine the effects of changing monomer concentration in reaction mixture on the values of primary structural parameters and macroscopic properties of the synthesized PMA xerogels, samples of PMA hydrogels

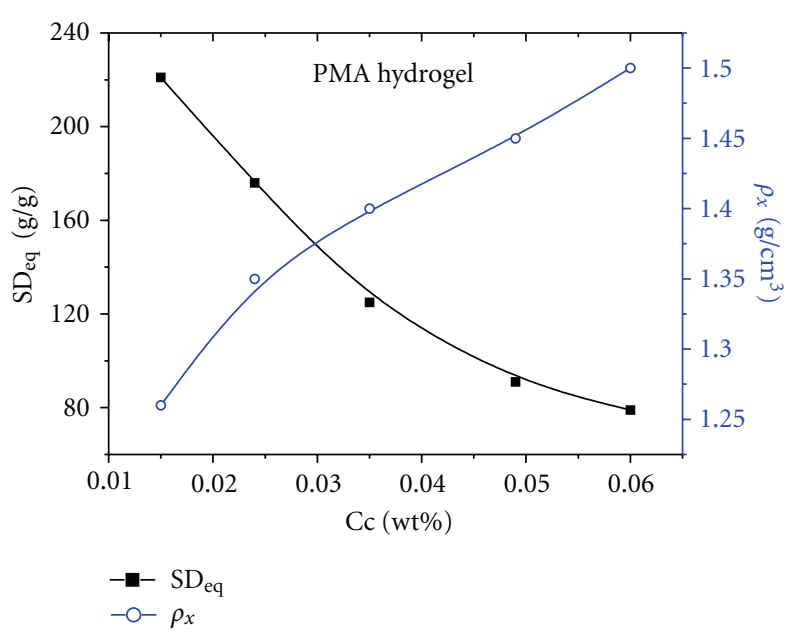

FIGURE 4: The effect of crosslinker concentration on the macroscopic properties of PMA xerogels.

TABLE 3: Effect of changes in Cc on primary structural parameters of PMA xerogels.

\begin{tabular}{lccc}
\hline $\mathrm{Cc}, \mathrm{wt} \%$ & $M_{c} \cdot 10^{-5}, \mathrm{~g} / \mathrm{mol}$ & $\rho_{c} \cdot 10^{4}, \mathrm{~mol} / \mathrm{cm}^{3}$ & $d, \mathrm{~nm}$ \\
\hline 0.015 & 2.7 & 3.5 & 290 \\
0.024 & 2.2 & 4.2 & 250 \\
0.035 & 1.4 & 6.7 & 180 \\
0.049 & 0.91 & 10.4 & 132 \\
0.060 & 0.75 & 11.7 & 118 \\
\hline
\end{tabular}

were synthesized. For that reason, reaction mixtures with monomer concentration varying within the range of 20$40 \mathrm{wt} \%$ were prepared and reactions proceed with constant all the others parameters $(\mathrm{Ci}=0.2 \mathrm{wt} \%, \mathrm{Cc}=0.04 \mathrm{wt} \%, \mathrm{ND}=$ $40 \%, T=80^{\circ} \mathrm{C}$, and $t=3 \mathrm{~h}$ ). Figure 5 presents the effects of monomer concentration on the MP of the synthesized PMA xerogels.

Table 4 summarizes the effects of monomer concentration on the MP and PSP of the synthesized PMA xerogels.

Likewise in the case of crosslinker concentration, the increase in the methacrylic acid concentration in the reaction mixture leads to the increase in the values of xerogel density and crosslinking density of xerogel, while the values of equilibrium swelling degree, average molar mass between crosslinks, and the distance between the macromolecular chains decrease.

The primary structural parameters and macroscopic properties of PMA xerogels are power functions on the monomer concentration. Functional dependences of MP and PSP on monomer concentration are given by the empirical Equation (18)

$$
\begin{aligned}
\mathrm{SD}_{\mathrm{eq}} & =2.7 \cdot 10^{6} C_{m}^{-3.18} \quad R=0.98, \\
\rho_{x} & =1.02 \cdot C_{m}^{0.09} \quad R=0.99, \\
M_{c} & =9.5 \cdot 10^{11} \cdot C_{m}^{-5.04} \quad R=0.98,
\end{aligned}
$$




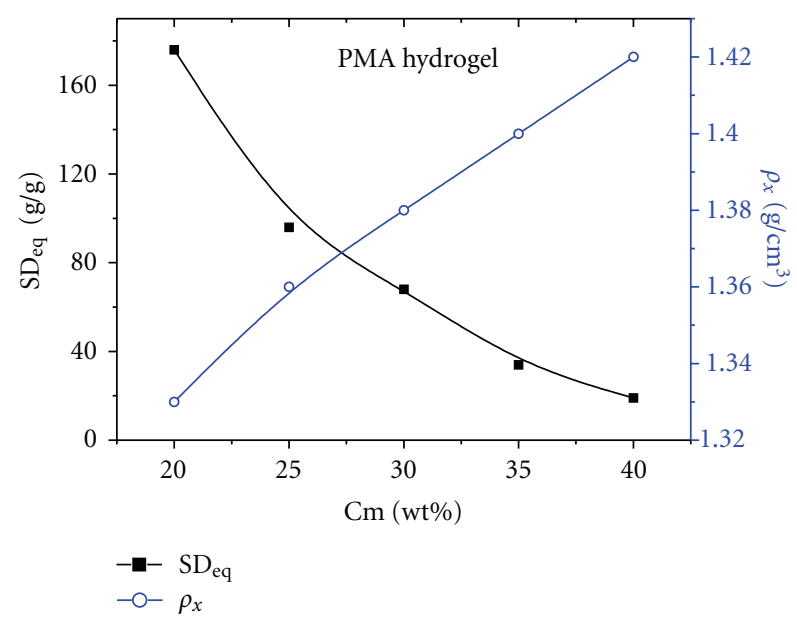

Figure 5: Effect of monomer concentration on macroscopic properties for PMA xerogels.

$$
\begin{array}{cc}
\rho_{c}=8.8 \cdot 10^{-11} \cdot C_{m}^{5.10} & R=0.98 \\
d=1.05 \cdot 10^{7} \cdot C_{m}^{-3.5} & R=0.97
\end{array}
$$

As was previously seen for crosslinker concentration, once again, the values of MP and PSP of synthesized PMA xerogels may be scaled with molar mass between crosslinks through scaling law (see (19))

$$
\begin{array}{cc}
\mathrm{SD}_{\mathrm{eq}}=0.08 \cdot M_{c}^{0.63} & R=0.99 \\
\rho_{x}=1.65 \cdot M_{c}^{0.02} & R=0.96 \\
\rho_{c}=99.5 \cdot M_{c}^{-1.0} & R=1.0 \\
d=0.05 \cdot M_{c}^{0.71} & R=0.99
\end{array}
$$

The established changes of MP and PSP with the increasing monomer concentration in reaction mixture can be attributed to the fact that the increasing $\mathrm{Cm}$ leads to the increase in the rate of crosslinking polymerization, which causes the decreased values of average molar mass between crosslinks, and crosslinking density of xerogel increases which has as consequence the increase in the xerogel density while the value of $\mathrm{SD}_{\mathrm{eq}}$ decreases.

\section{Design of Poly(Acrylic Acid)- G-Gelatin Xerogel Synthesis via Crosslinking Graft Polymerization}

6.1. Synthesis of Poly(Acrylic Acid)-G-Gelatin Hydrogels. A series of poly(acrylic acid)-g-gelatin (PAAG) xerogels with different neutralization degrees (ND) of acrylic acid and different crosslinker (MBA) concentration were synthesized via crosslinking graft polymerization of AA onto gelatin. The procedure of synthesis goes as follows. Firstly, $0.5 \mathrm{~g}$ of gelatin (Gelatin (70-100 Blooma), puriss, Kemika d.d. Zagreb, Croatia) was dissolved in $35 \mathrm{~mL}$ of distilled water
TABLE 4: Effect of monomer concentration on primary structural parameters of PMA xerogels.

\begin{tabular}{lccc}
\hline $\mathrm{Cm}, \mathrm{wt} \%$ & $M_{c} \cdot 10^{-4}, \mathrm{~g} / \mathrm{mol}$ & $\rho_{c} \cdot 10^{4}, \mathrm{~mol} / \mathrm{cm}^{3}$ & $d, \mathrm{~nm}$ \\
\hline 20 & 22 & 4.2 & 250 \\
25 & 8.8 & 4.8 & 134 \\
30 & 5.1 & 19 & 88 \\
35 & 1.6 & 66 & 40 \\
40 & 0.64 & 149 & 21 \\
\hline
\end{tabular}

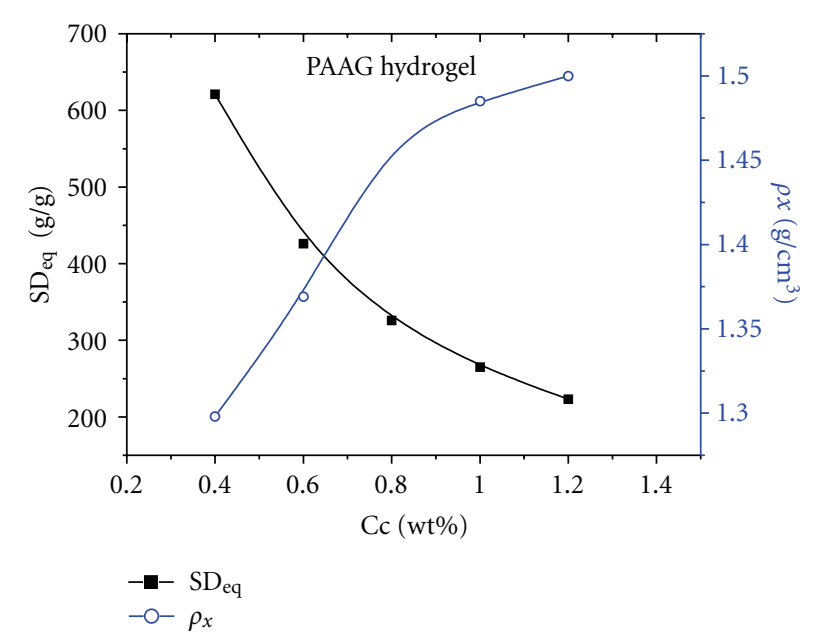

Figure 6: The effects of Cc on MP of PAAG xerogels.

at $45^{\circ} \mathrm{C}$ under stirring, until clear, homogenous solution was performed. Then, the initiator solution (VA-044, 1\% wt) was added to gelatin solution and left for $15 \mathrm{~min}$ under stirring. In the meantime, AA was neutralized to required degree of neutralization, by dropwise adding potassium hydroxide aqueous solution $(50 \mathrm{wt} \%)$ under cooling $\left(5^{\circ} \mathrm{C}\right)$ with constant stirring. After that, crosslinker $(0.1 \mathrm{wt} \%)$ was added and subsequently was added to the gelatine-initiator solution. The reaction mixture was once again rapidly stirred and immediately poured into teflons mold and placed in a thermostated oven at $80^{\circ} \mathrm{C}$, for 3 hours.

After the completion the reaction, the resulting products were handled in the same way as the PAA hydrogel.

The primary structural parameters and macroscopic properties were determined using the methods given for the PAA xerogels.

6.2. The Effects of Crosslinker Concentration on MP and PSP of $P A A G$ Xerogel. The effect of crosslinker concentration on the primary structural parameters and properties of poly(acrylic acid-g-gelatine (PAAG) xerogels was investigated within the range of crosslinker concentration varying from $0.4 \mathrm{wt} \%-$ $1.2 \mathrm{wt} \%$ respective to monomer AA. The samples were synthesized keeping constant all other reaction parameters $\left(\mathrm{Cm}=30 \mathrm{wt} \%, \mathrm{Ci}=1.0 \mathrm{wt} \%, \mathrm{ND}=50 \%, C_{g}=5 \mathrm{wt} \% \mathrm{~T}=\right.$ $80^{\circ} \mathrm{C}$, and $t=3 \mathrm{~h}$ ). The changes of values of MP of PAAG xerogels with change in the Cc are shown in Figure 6. 
The changes of values of PSP of PAAG xerogels with change in the $\mathrm{Cc}$ are presented in Table 5.

The results above presented reveal that the increase in crosslinker concentration has the same effect on MP and PSP of PAAG xerogels as in the case of both PAA and PMA xerogels. In fact, once again, the increasing crosslinker concentration leads to the increasing values of xerogel density and network's crosslinking density on the contrary to the decreasing values of equilibrium swelling degrees, average molar mass between crosslinks and the distance between the macromolecular chains.

The relationships between crosslinker concentration in reaction mixture and the primary structural parameters and properties of the synthesized PAAG xerogels are found to be as follows:

$$
\begin{aligned}
\mathrm{SD}_{\mathrm{eq}} & =265 \cdot C_{c}^{-0.93} \quad R=0.99, \\
\rho_{x} & =1.49 \cdot C_{c}^{0.15} \quad R=0.98, \\
M_{c} & =6.5 \cdot 10^{5} \cdot C_{c}^{-1.08} \quad R=0.97 \\
\rho_{c} & =2.31 \cdot 10^{-3} \cdot C_{c}^{1.25} \quad R=0.98 \\
d & =260 \cdot C_{c}^{-0.78} \quad R=0.97 .
\end{aligned}
$$

Scaling law of MP and PSP with $M_{c}$ was found and given with empirical Equations (21)

$$
\begin{aligned}
\mathrm{SD}_{\mathrm{eq}} & =4.3 \cdot 10^{-3} \cdot M_{c}^{0.83} \quad R=0.99, \\
\rho_{x} & =8.6 \cdot M_{c}^{-0.13} \quad R=0.94 \\
\rho_{c} & =1.1 \cdot 10^{4} \cdot M_{c}^{-1.15} \quad R=0.99 \\
d & =0.016 \cdot M_{c}^{0.72} \quad R=0.99 .
\end{aligned}
$$

The found changes in MP and PSP of xerogels synthesized by the crosslinking polymerization with the increased crosslinker concentration can be explained as follows. With the increase in crosslinker concentration, the network crosslinking density increases, which in turn causes the decrease in $M_{c}$ and $d$, while the xerogel density and $\mathrm{SD}_{\mathrm{eq}}$ decrease.

6.3. The Effects of Neutralization Degree on MP and PSP of $P A A G$ Xerogel. The samples of PAAG xerogels with different degrees of neutralization from $0 \%-100 \%$ were synthesized by varying neutralization degree of $\mathrm{AA}$ while the other reaction parameters were kept constant $(\mathrm{Cm}=30 \mathrm{wt} \%, \mathrm{Cc}=$ $0.8 \mathrm{wt} \%, \mathrm{Ci}=0.27 \mathrm{wt} \%, C_{g}=5 \mathrm{wt} \%, T=80^{\circ} \mathrm{C}$, and $t=3 \mathrm{~h}$ ) aimed at investigating the effects of neutralization degree on MP and PSP of PAAG xerogels. The effect of neutralization degree on MP of PAAG xerogels are shown in Figure 7.

Table 6 presents the effect of neutralization degree on PSP of PAAG xerogels.

It is clear that the increasing degree of neutralization of acrylic acid results in xerogels with increased values of $M_{c}$, $d$, and $\mathrm{SD}_{\mathrm{eq}}$ and decreased values of crosslinking density of xerogel and xerogel density. The found changes in the MP and PSP values of synthesized xerogels, like in the
TABLE 5: The effect of Cc on primary structural parameters of PAAG xerogels.

\begin{tabular}{lccc}
\hline Cc, wt $\%$ & $M_{c} \cdot 10^{-6}, \mathrm{~g} / \mathrm{mol}$ & $\rho_{c}, \mathrm{~mol} \cdot 10^{3} / \mathrm{cm}^{3}$ & $d, \mathrm{~nm}$ \\
\hline 0.4 & 1.59 & 0.80 & 503 \\
0.6 & 1.27 & 1.08 & 426 \\
0.8 & 0.82 & 1.73 & 310 \\
1.0 & 0.72 & 2.03 & 284 \\
1.2 & 0.46 & 3.34 & 205 \\
\hline
\end{tabular}

case of effects of crosslinker concentration, revealed power functional relationships with the degree of neutralization, as can be seen from the following empirical Equation (22)

$$
\begin{array}{cc}
\mathrm{SD}_{\mathrm{eq}}=15.33 \cdot \mathrm{ND}^{0.79} & R=0.99, \\
\rho_{x}=2.27 \cdot \mathrm{ND}^{-0.12} & R=0.99, \\
M_{c}=1.56 \cdot 10^{4} \cdot \mathrm{ND}^{0.99} \quad R=0.99 \\
\rho_{c}=0.15 \cdot \mathrm{ND}^{-1.17} \quad R=0.99 \\
d=17.6 \cdot \mathrm{ND}^{0.72} \quad R=0.99 .
\end{array}
$$

The existence of scaling law between the values of MP and PSP of PAAG xerogels with different degrees of neutralization of acrylic acid and $M_{c}$ is given with empirical Equation (23)

$$
\begin{gathered}
\mathrm{SD}_{\mathrm{eq}}=1.5 \cdot 10^{-4} \cdot M_{c}^{1.08} \quad R=0.99, \\
\rho_{x}=3.16 \cdot M_{c}^{-0.06} \quad R=0.93 \\
\rho_{c}=1.71 \cdot M_{c}^{-1.87} \quad R=0.99 \\
d=2.7 \cdot 10^{-5} M_{c}^{1.19} \quad R=0.99 .
\end{gathered}
$$

Flory described the mechanism of the swelling of ionic networks [68]. According to Flory's theory, if the polymer chains making up the network containing ionizable group, the swelling forces may be greatly increased as a result of the localization of charges on the polymer chains and their repulsion effects. When acrylic acid is neutralized with $\mathrm{KOH}$, the negatively charged carboxyl groups attached to the polymer chains set up an electrostatic repulsion which tends to expand the network. Therefore, if the increasing neutralization degree results in decrease of electrostatic repulsion between the polymer chains, then the $\mathrm{SD}_{\mathrm{eq}}$ will decrease also.

On the contrary, however, during the CLGP of acrylic acid and gelatin, the increased degree of neutralization of AA increases the contraction of $\mathrm{K}$-acrylate in reaction mixture. Bearing in mind that during the CLGP, the dominant effect on the structure of formed polymer network have the process of intermolecular cyclization, it is logical to propose that the increased degree of neutralization, that is, the $\mathrm{K}$ acrylate concentration results in increased values of average molar mass between crosslinks and the distance between the macromolecular chains. Therefore, the values of crosslinking density and xerogel density of the synthesized xerogels are decreased, while the values of $\mathrm{SD}_{\mathrm{eq}}$ are increased. 


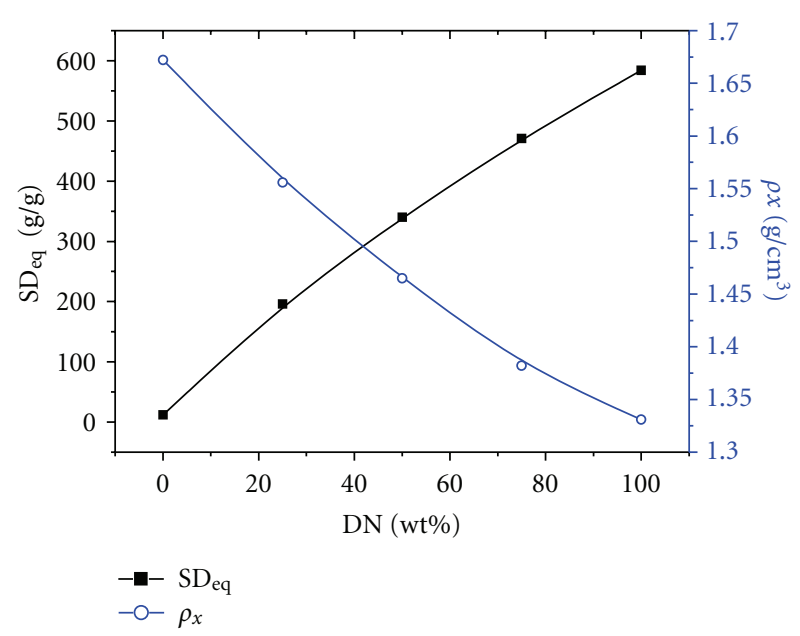

Figure 7: Effect of degree of neutralization on macroscopic properties of PAAG xerogels.

TABLE 6: The effect of neutralization degree on PSPP of PAAG xerogels.

\begin{tabular}{lccc}
\hline $\mathrm{DN}, \mathrm{wt} \%$ & $M_{c} \cdot 10^{-5}, \mathrm{~g} / \mathrm{mol}$ & $\rho_{c} \cdot 10^{3}, \mathrm{~mol} / \mathrm{cm}^{3}$ & $d, \mathrm{~nm}$ \\
\hline 0 & 0.41 & 411 & 7 \\
25 & 3.85 & 4.04 & 180 \\
50 & 8.23 & 1.78 & 310 \\
75 & 12.14 & 1.14 & 412 \\
100 & 15.10 & 0.87 & 485 \\
\hline
\end{tabular}

The effects of reaction conditions on crosslinking density and equilibrium swelling for xerogels samples synthesized by radical polymerization (RP), crosslinking polymerization (CLP), and crosslinking graft polymerization (CLPG) were evaluated in numerous of theoretical considerations [68-70].

According to the model of ionic networks proposed by Flory [71], it is predictable that the dependence of equilibrium swelling degree on crosslinker concentration is in power law form, given by

$$
\mathrm{SD}_{\mathrm{eq}}=k \cdot C_{c}^{-0.6} \text {. }
$$

This dependence is experimentally confirmed by Chen and Zhao, for CLP of acrylic acid [72], and Pourjavadi et al., for CLPG of acrylic acid onto kappa-carageenan [73]. Pacios et al. found stoichiometry relationship between crosslink density of product and total concentration of comonomers and crosslinker concentration for the CLP of $n$-vynilimidizol [74]. For the same system, Obukhov et al. [75] found that equilibrium swelling degree is power function of monomer concentrations in reaction mixture

$$
\mathrm{SD}_{\mathrm{eq}} \propto C_{m}^{-b}
$$

where $b$ is parameters depending of solvent; in good solvent $b=1$ and in theta solvent $b=3 / 4$.

Table 7 summarizes values of prefactor $(a)$ and exponent (b) calculated for established power function of the PSPP on different reaction conditions, for the investigated process of polymerization.
The results presented in Table 7 reveal that the values of prefactor $(a)$ and exponent $(b)$ for each particular MP and PSP are dependent on the method of polymerization and reaction conditions, and accordingly, they cannot be used as a base for making a general model that would be applied to predict the MP and PSP of xerogels that would be synthesized.

Furukawa [76] investigated effects of reaction conditions on $\mathrm{SD}_{\mathrm{eq}}$ for CLP of poly(acrylamide) and established the following relationship:

$$
\mathrm{SD}_{\mathrm{eq}} \propto N^{3 v-1},
$$

where $N$ means polymerization index and $v$ is parameter of the deGenne's blob model [77]. The $v=3 / 5$ in good solvent and $v=1 / 2$ in theta solvent).

In all of the above evaluated crosslinking-polymerization systems, it is established that MP and PSP can be scaled with $M_{c}$. The values of prefactor and scaling exponent are given in Table 8.

The results presented in Table 8 show that the scaling exponent presents a constant value within the experimental error for CLP even in the case when deferent monomers are used and different reaction conditions are applied. That value considerably differs than the value for the exponent obtained for CLGP. Therefore, we may conclude that for the particular type of polymerization the model for prediction the PSP has to be based on the scaling law of PSP and $M_{c}$, because the $M_{c}$ is the basic structural detail of synthesized xerogel.

The generality in that law presents the equality of the value of exponent $b$ for the xerogels synthesized by the same method of polymerization and that value present a global physical property of the obtained xerogel and implies on the way of scaling structural property of xerogel.

In contrast to this, the prefactor $a$ in scaling law is not universal. The prefactor $a$ depends on the structural details of xerogel and accordingly is changeable depending on type of polymerization and reaction conditions and type of monomer.

The established functional dependences of PSP on reaction condition for different methods of polymerization and the possibility of their scaling with $M_{c}$ enable us to model directed synthesis of xerogels/hydrogels. That modeling, as was previously said, is based on (13) and (30) which serves for calculation reaction conditions for synthesis of xerogel with predetermined macroscopic properties.

Based on the suggested "model of synthesis design", the selection of reaction conditions under which will be synthesized xerogel with predefined macroscopic properties is performed in two steps. Firstly, the values of molar mass between crosslinks which generate desired macroscopic property of xerogel, are calculated by (14) and in the following step, the reaction condition which will results in synthesis of xerogel with desired $M_{c}$ is performed according to (15).

\section{Conclusions}

In all of the investigated methods of synthesis xerogels/hydrogels (CLP, CCLP, and CLPG), the existence of 
TABLE 7: The values of prefactor and exponent for established power function of the MP PSP on different reaction conditions.

\begin{tabular}{lcccccccccccc}
\hline \multirow{2}{*}{ Xerogel } & \multirow{2}{*}{ Reaction parmeter } & \multicolumn{2}{c}{$\mathrm{SD}_{\mathrm{eq}}$} & \multicolumn{2}{c}{$\rho_{x}$} & \multicolumn{2}{c}{$M_{c}$} & \multicolumn{2}{c}{$\rho_{c}$} & \multicolumn{2}{c}{$d$} \\
& & $a$ & $b$ & $a$ & $b$ & $A$ & $b$ & $a$ & $b$ & $a$ \\
\hline PAA & $\mathrm{Cc}$ & 32.5 & -0.40 & 2.02 & 0.06 & $3.3 \cdot 10^{4}$ & -0.50 & 60 & 0.59 & 47 \\
PMA & $\mathrm{Cc}$ & 0.152 & -1.26 & 4.05 & 0.20 & 33.44 & -1.56 & 2.83 & 1.57 & 0.42 & -1.14 \\
PAAG & $\mathrm{Cc}$ & 265 & -0.93 & 1.49 & 0.15 & $6.5 \cdot 10^{5}$ & -1.08 & $2.31 \cdot 10^{-3}$ & 1.25 & 260 & -0.78 \\
PAA & $\mathrm{Ci}$ & 750 & -0.87 & 1.35 & -0.09 & $2.5 \cdot 10^{6}$ & 1.23 & 0.54 & -1.32 & 1053 & 0.89 \\
PMA & $\mathrm{Cm}$ & $2.7 \cdot 10^{6}$ & -3.18 & 1.02 & 0.1 & $9.5 \cdot 10^{11}$ & -5.04 & $8.8 \cdot 10^{-11}$ & 5.10 & $1.05 \cdot 10^{7}$ & -3.50 \\
PAAG & $\mathrm{ND}$ & 15.33 & 0.79 & 2.27 & -0.12 & $1.56 \cdot 10^{4}$ & 0.99 & 0.15 & -1.17 & 17.6 & 0.72 \\
\hline
\end{tabular}

TABLE 8: The values of prefactor and scaling exponent of the MP and PSP on $M_{c}$.

\begin{tabular}{lccccccccc}
\hline \multirow{2}{*}{ Xerogel } & \multirow{2}{*}{ Reaction parmeter } & \multicolumn{2}{c}{$\mathrm{SD}_{\mathrm{eq}}$} & \multicolumn{3}{c}{$\rho_{x}$} & \multicolumn{2}{c}{$\rho_{c}$} & \multicolumn{1}{c}{$d$} \\
& & $a$ & $B$ & $a$ & $b$ & $a$ & -1.1 & 0.02 \\
\hline PAA & $\mathrm{Cc}$ & 0.015 & 0.74 & 4.95 & -0.10 & 5.44 & 0.73 \\
PMA & $\mathrm{Cc}$ & 0.01 & 0.79 & 5.6 & -0.12 & 100 & -1.0 & 0.03 & 0.73 \\
PAAG & $\mathrm{Cc}$ & $4.3 \cdot 10^{-3}$ & 0.83 & 8.6 & -0.13 & $1.1 \cdot 10^{4}$ & -1.15 & 0.016 & 0.72 \\
PAA & $\mathrm{Ci}$ & 0.02 & 0.71 & 3.85 & -0.07 & 3.83 & -1.07 & 0.03 & 0.72 \\
PMA & $\mathrm{Cm}$ & 0.08 & 0.63 & 1.65 & 002 & 99.5 & -1.0 & 0.05 & 0.71 \\
PAAG & $\mathrm{ND}$ & $1.5 \cdot 10^{-4}$ & 1.08 & 3.16 & -0.06 & 1.7 & -1.87 & $2.7 \cdot 10^{-5}$ & 1.19 \\
\hline
\end{tabular}

empirical functional relationships between reaction conditions (concentration of crosslinker, monomer and initiator, and degree of neutralization of monomer), values of structural parameters of xerogel $\left(M_{c}, d\right.$, and crosslinking density of network), and macroscopic properties (xerogel density and equilibrium swelling degree) are found.

In all of the investigated methods of polymerization, the presence of functional relationship between reaction conditions (RCi) and primary structural parameters and properties $\left(\mathrm{PSP}_{j}\right)$ of power form and power function was established

$$
\operatorname{PSP}_{j}=a \cdot R C_{i}^{b}
$$

The values of parameters ( $a$ and $b$ ) of the above power function are dependent on the method of polymerization, monomer type, and reaction conditions.

For all of the investigated process, the possibility of scaling of MP and PSP with $M_{c}$ is reveled.

The values of scaling exponent of that function for the same method of polymerization are independent on the monomer type and other reaction condition and present a structural parameter of the xerogel. The $M_{c}$ is structural parameter based on which may be predicted macroscopic physicochemical properties of xerogels and their application in tissue engineering.

\section{Acknowledgment}

This investigation was supported by the Ministry of Science and Technical Development of the Republic of Serbia through Project no. 172015 OI.

\section{References}

[1] J. J. Grodzinski, "Polymeric gels and hydrogels for biomedical and pharmaceutical applications," Polymers for Advanced Technologies, vol. 21, no. 1, pp. 27-47, 2010.

[2] R. Langer and D. A. Tirrell, "Designing materials for biology and medicine," Nature, vol. 428, no. 6982, pp. 487-492, 2004.

[3] E. S. Place, N. D. Evans, and M. M. Stevens, "Complexity in biomaterials for tissue engineering," Nature Materials, vol. 8, no. 6, pp. 457-470, 2009.

[4] N. A. Peppas and A. G. Mikos, "Preparation methods and structure of hydrogels," in Hydrogels in Medicine and Pharmacy, N. A. Peppas, Ed., pp. 2-23, CRC Press, Boca Raton, Fla, USA, 1986.

[5] K. Park, W. C. W. Shalaby, and H. Park, "Hydrogels, definition, hydrogel as a biomaterial, biodegradable hydrogels, biodegradation," in Biodegradable Hydrogels for Drug Delivery, K. Park, W. C. W. Shalaby, and H. Park, Eds., pp. 1-12, Technomic, Lancaster, UK, 1993.

[6] S. Chaterji, I. K. Kwon, and K. Park, "Smart polymeric gels: redefining the limits of biomedical devices," Progress in Polymer Science, vol. 32, no. 8-9, pp. 1083-1122, 2007.

[7] A. Kikuchi and T. Okano, "Pulsatile drug release control using hydrogels," Advanced Drug Delivery Reviews, vol. 54, no. 1, pp. 53-77, 2002.

[8] S. H. Hu, T. Y. Liu, D. M. Liu, and S. Y. Chen, "Controlled pulsatile drug release from a ferrogel by a high-frequency magnetic field," Macromolecules, vol. 40, no. 19, pp. 67866788, 2007.

[9] D. S. Kohane and R. Langer, "Polymeric biomaterials in tissue engineering," Pediatric Research, vol. 63, no. 5, pp. 487-491, 2008.

[10] J. F. Mano, "Stimuli-responsive polymeric systems for biomedical applications," Advanced Engineering Materials, vol. 10, no. 6, pp. 515-527, 2008. 
[11] M. Yamato, C. Konno, M. Utsumi, A. Kikuchi, and T. Okano, "Thermally responsive polymer-grafted surfaces facilitate patterned cell seeding and co-culture," Biomaterials, vol. 23, no. 2, pp. 561-567, 2002.

[12] Y. Yeo and D. S. Kohane, "Polymers in the prevention of peritoneal adhesions," European Journal of Pharmaceutics and Biopharmaceutics, vol. 68, no. 1, pp. 57-66, 2008.

[13] N. E. Fedorovich, J. Alblas, J. R. de Wijn, W. E. Hennink, A. B.J. Verbout, and W. J.A. Dhert, "Hydrogels as extracellular matrices for skeletal tissue engineering: state-of-the-art and novel application in organ printing," Tissue Engineering, vol. 13, no. 8, pp. 1905-1925, 2007.

[14] S. Möller, J. Weisser, S. Bischoff, and M. Schnabelrauch, “Dextran and hyaluronan methacrylate based hydrogels as matrices for soft tissue reconstruction," Biomolecular Engineering, vol. 24, no. 5, pp. 496-504, 2007.

[15] E. Ho, A. Lowman, and M. Marcolongo, "Synthesis and characterization of an injectable hydrogel with tunable mechanical properties for soft tissue repair," Biomacromolecules, vol. 7, no. 11, pp. 3223-3228, 2006.

[16] W. Lee, D. Choi, Y. Lee, D. N. Kim, J. Park, and W. G. Koh, "Preparation of micropatterned hydrogel substrate via surface graft polymerization combined with photolithography for biosensor application," Sensors and Actuators, B, vol. 129, no. 2, pp. 841-849, 2008.

[17] J. Hoffmann, M. Plotner, D. Kucling, and W.-J. Fischer, "Photopatterning of thermally sensitive hydrogel useful for micro actuators," Sens Actuators, vol. 77, pp. 139-144, 1999.

[18] J. D. Kretlow, L. Klouda, and A. G. Mikos, "Injectable matrices and scaffolds for drug delivery in tissue engineering," Advanced Drug Delivery Reviews, vol. 59, no. 4-5, pp. 263-273, 2007.

[19] Z. M. O. Rzaev, S. Dinçer, and E. Pişkin, "Functional copolymers of $\mathrm{N}$-isopropylacrylamide for bioengineering applications," Progress in Polymer Science, vol. 32, no. 5, pp. 534-595, 2007.

[20] J. L. Drury and D. J. Mooney, "Hydrogels for tissue engineering: scaffold design variables and applications," Biomaterials, vol. 24, no. 24, pp. 4337-4351, 2003.

[21] S. Varghese and J. H. Elisseeff, "Hydrogels for musculoskeletal tissue engineering," Advances in Polymer Science, vol. 203, no. 1, pp. 95-144, 2006.

[22] K. Tuzlakoglu, C. M. Alves, J. F. Mano, and R. L. Reis, "Production and characterization of chitosan fibers and 3D fiber mesh scaffolds for tissue engineering applications," Macromolecular Bioscience, vol. 4, no. 8, pp. 811-819, 2004.

[23] T. Guo, J. Zhao, J. Chang et al., "Porous chitosan-gelatin scaffold containing plasmid DNA encoding transforming growth factor- $\beta 1$ for chondrocytes proliferation," Biomaterials, vol. 27, no. 7, pp. 1095-1103, 2006.

[24] Y. Liu and M. B. Chan-Park, "Hydrogel based on interpenetrating polymer networks of dextran and gelatin for vascular tissue engineering," Biomaterials, vol. 30, no. 2, pp. 196-207, 2009.

[25] S. Young, M. Wong, Y. Tabata, and A. G. Mikos, "Gelatin as a delivery vehicle for the controlled release of bioactive molecules," Journal of Controlled Release, vol. 109, no. 1-3, pp. 256-274, 2005.

[26] F. M. Chen, Y. M. Zhao, H. H. Sun et al., "Novel glycidyl methacrylated dextran (Dex-GMA)/gelatin hydrogel scaffolds containing microspheres loaded with bone morphogenetic proteins: formulation and characteristics," Journal of Controlled Release, vol. 118, no. 1, pp. 65-77, 2007.
[27] F. M. Chen, Y. M. Zhao, R. Zhang et al., "Periodontal regeneration using novel glycidyl methacrylated dextran (DexGMA)/gelatin scaffolds containing microspheres loaded with bone morphogenetic proteins," Journal of Controlled Release, vol. 121, no. 1-2, pp. 81-90, 2007.

[28] J. D. Kosmala, D. B. Henthorn, and L. Brannon-Peppas, "Preparation of interpenetrating networks of gelatin and dextran as degradable biomaterials," Biomaterials, vol. 21, no. 20, pp. 2019-2023, 2000.

[29] Y. Lu, D. Wang, T. Li et al., "Poly(vinyl alcohol)/poly(acrylic acid) hydrogel coatings for improving electrode-neural tissue interface," Biomaterials, vol. 30, no. 25, pp. 4143-4151, 2009.

[30] K. Y. Lee and D. J. Mooney, "Hydrogels for tissue engineering," Chemical Reviews, vol. 101, no. 7, pp. 1869-1879, 2001.

[31] Y. Teramura, Y. Kaneda, and H. Iwata, "Islet-encapsulation in ultra-thin layer-by-layer membranes of poly(vinyl alcohol) anchored to poly(ethylene glycol)-lipids in the cell membrane," Biomaterials, vol. 28, no. 32, pp. 4818-4825, 2007.

[32] D. Mawad, P. J. Martens, R. A. Odell, and L. A. Poole-Warren, "The effect of redox polymerisation on degradation and cell responses to poly (vinyl alcohol) hydrogels," Biomaterials, vol. 28, no. 6, pp. 947-955, 2007.

[33] J. Choi, H. Bodugoz-Senturk, H. J. Kung, A. S. Malhi, and O. K. Muratoglu, "Effects of solvent dehydration on creep resistance of poly(vinyl alcohol) hydrogel," Biomaterials, vol. 28, no. 5, pp. 772-780, 2007.

[34] Y. M. Yue, K. Xu, X. G. Liu, Q. Chen, X. Sheng, and P. X. Wang, "Preparation and characterization of interpenetration polymer network films based on poly(vinyl alcohol) and poly(acrylic acid) for drug delivery," Journal of Applied Polymer Science, vol. 108, no. 6, pp. 3836-3842, 2008.

[35] E. De Giglio, S. Cometa, N. Cioffi, L. Torsi, and L. Sabbatini, "Analytical investigations of poly(acrylic acid) coatings electrodeposited on titanium-based implants: a versatile approach to biocompatibility enhancement," Analytical and Bioanalytical Chemistry, vol. 389, no. 7-8, pp. 2055-2063, 2007.

[36] J. Dai, Z. Bao, L. Sun, S. U. Hong, G. L. Baker, and M. L. Bruening, "High-capacity binding of proteins by poly(acrylic acid) brushes and their derivatives," Langmuir, vol. 22, no. 9, pp. 4274-4281, 2006.

[37] J. A. Hubbell, "Bioactive biomaterials," Current Opinion in Biotechnology, vol. 10, no. 2, pp. 123-129, 1999.

[38] J. A. Rowley, G. Madlambayan, and D. J. Mooney, "Alginate hydrogels as synthetic extracellular matrix materials," Biomaterials, vol. 20, no. 1, pp. 45-53, 1999.

[39] D. L. Hern and J. A. Hubbell, "Incorporation of adhesion peptides into nonadhesive hydrogels useful for tissue resurfacing," Journal of Biomedical Materials Research, vol. 39, no. 2, pp. 266-276, 1998.

[40] B. K. Mann, R. H. Schmedlen, and J. L. West, "Tethered-TGF$\beta$ increases extracellular matrix production of vascular smooth muscle cells," Biomaterials, vol. 22, no. 5, pp. 439-444, 2001.

[41] Y. Suzuki, M. Tanihara, K. Suzuki, A. Saitou, W. Sufan, and Y. Nishimura, "Alginate hydrogel linked with syntheticoligiopeptide derived from BMP-2 allows ectopic osteoinduction in vivo," Journal of Biomedical Materials Research, vol. 50, pp. 405-409, 2000.

[42] J. Elisseeff, W. McIntosh, K. Fu, T. Blunk, and R. Langer, "Controlled-release of IGF-I and TGF- $\beta 1$ in a photopolymerizing hydrogel for cartilage tissue engineering," Journal of Orthopaedic Research, vol. 19, no. 6, pp. 1098-1104, 2001.

[43] A. E. Bent, J. Foote, S. Siegel, G. Faerber, R. Chao, and E. A. Gormley, "Collagen implant for treating stress urinary 
incontinence in women with urethral hypermobility," Journal of Urology, vol. 166, no. 4, pp. 1354-1357, 2001.

[44] C. R. Nuttelman, D. J. Mortisen, S. M. Henry, and K. S. Anseth, "Attachment of fibronectin to poly(vinyl alcohol) hydrogels promotes NIH3T3 cell adhesion, proliferation, and migration," Journal of Biomedical Materials Research, vol. 57, no. 2, pp. 217-223, 2001.

[45] R. C. Thomson, M. C. Wake, M. J. Yaszemski, and A. G. Mikos, "Biodegradable polymer scaffolds to regenerate organs," Advances in Polymer Science, vol. 122, pp. 245-274, 1995.

[46] M. Dimitrov, N. Lambov, S. Shenkov, V. Dosseva, and V. Y. Baranovski, "Hydrogels based on the chemically crosslinked polyacrylic acid: biopharmaceutical characterization," Acta Pharmaceutica, vol. 53, no. 1, pp. 25-31, 2003.

[47] M. Changez, V. Koul, B. Krishna, A. K. Dinda, and V. Choudhary, "Studies on biodegradation and release of gentamicin sulphate from interpenetrating network hydrogels based on poly(acrylic acid) and gelatin: in vitro and in vivo," Biomaterials, vol. 25, no. 1, pp. 139-146, 2004.

[48] J. S. Ahn, H. K. Choi, M. K. Chun et al., "Release of triamcinolone acetonide from mucoadhesive polymer composed of chitosan and poly(acrylic acid) in vitro," Biomaterials, vol. 23, no. 6, pp. 1411-1416, 2002.

[49] Z. Juranic, L. Stevovic, B. Drakulic, T. Stanojkovic, S. Radulovic, and I. Juranic, "Substituted (E)-(benzoil) acrylic acid suppressed survival of neoplastic HeLacels," Journal of the Serbian Chemical Society, vol. 64, no. 9, pp. 505-512, 1999.

[50] B. Adnadjevic, J. Jovanovic, and B. Drakulic, "Isothermal kinetics of (E)-4-(4-metoxyphenyl)-4-oxo-2-butenoic acid release from poly(acrylic acid) hydrogel," Thermochimica Acta, vol. 466, no. 1-2, pp. 38-48, 2007.

[51] B. Adnadjevic and J. Jovanovic, "A comparative kinetics study of isothermal drug release from poly(acrylic acid) and poly(acrylic-co-methacrylic acid) hydrogels," Colloids and Surfaces B, vol. 69, no. 1, pp. 31-42, 2009.

[52] K. M. Gupta, S. R. Barnes, R. A. Tangaro et al., "Temperature and $\mathrm{pH}$ sensitive hydrogels: an approach towards smart semen-triggered vaginal microbicidal vehicles," Journal of Pharmaceutical Sciences, vol. 96, no. 3, pp. 670-681, 2007.

[53] M. Dittgen, M. Durrani, and K. Lehmann, "Acrylic polymers - a review of pharmaceutical applications," S.T.P. Pharma Sciences, vol. 7, no. 6, pp. 403-437, 1997.

[54] A. Besheer, K. M. Wood, N. A. Peppas, and K. Mäder, "Loading and mobility of spin-labeled insulin in physiologically responsive complexation hydrogels intended for oral administration," Journal of Controlled Release, vol. 111, no. 12, pp. 73-80, 2006.

[55] D. F. Williams, "On the mechanisms of biocompatibility," Biomaterials, vol. 29, no. 20, pp. 2941-2953, 2008.

[56] J. Kopeček and J. Yang, "Hydrogels as smart biomaterials," Polymer International, vol. 56, no. 9, pp. 1078-1098, 2007.

[57] A. S. Hoffman, "Hydrogels for biomedical applications," Advanced Drug Delivery Reviews, vol. 54, no. 1, pp. 3-12, 2002.

[58] F. Lim, "Microencapsulation of living cells and tissuestheory and practice," in Biomedical Applications of Microencapsulation, pp. 137-154, CRC Press, Boca Raton, Fla, USA, 1984.

[59] F. Brandl, F. Sommer, and A. Goepferich, "Rational design of hydrogels for tissue engineering: impact of physical factors on cell behavior," Biomaterials, vol. 28, no. 2, pp. 134-146, 2007.

[60] M. S. Shoichet, "Polymer scaffolds for biomaterials applications," Macromolecules, vol. 43, no. 2, pp. 581-591, 2010.
[61] P. J. Flory and J. Rehner, "Statistical mechanics of crosslinked polymer networks I. Rubberlike elasticity," The Journal of Chemical Physics, vol. 11, no. 11, pp. 512-520, 1943.

[62] J. Brandrup and E. H. Immergut, Polymer Handbook, John Wiley \& Sons, New York, NY, USA, 2nd edition, 1975.

[63] H. R. Allcock and W. L. Frederick, Contemporary Polymer Chemistry, Prentice Hall, Englewood Cliffs, NJ, USA, 1981.

[64] H. Tobita and A. E. Hamielec, "Control of network structure in free-radical crosslinking copolymerization," Polymer, vol. 33, no. 17, pp. 3647-3657, 1992.

[65] K. Dusek, "Network formation involving polyfunctional polymer chains," in Polymer Networks: Principles of Their Formation Structure and Properties, R. F. T. Stepto, Ed., pp. 6492, Blackie Academic and Professional, London, UK, 1998.

[66] J. E. Elliott and C. N. Bowman, "Kinetics of primary cyclization reactions in cross-linked polymers: an analytical and numerical approach to heterogeneity in network formation," Macromolecules, vol. 32, no. 25, pp. 8621-8628, 1999.

[67] B. Adnadjevic and J. Jovanovic, "Novel approach in investigation of the poly(acrylic acid) hydrogel swelling kinetics in water," Journal of Applied Polymer Science, vol. 107, no. 6, pp. 3579-3587, 2008.

[68] L. Bromberg, A. Y. Grosberg, E. S. Matsuo, Y. Suzuki, and T. Tanaka, "Dependency of swelling on the length of subchain in poly(N,N-dimethylacrylamide)-based gels," Journal of Chemical Physics, vol. 106, no. 7, pp. 2906-2910, 1997.

[69] A. Pastoriza, I. E. Pacios, and I. F. Piérola, "Kinetics of solvent responsiveness in poly(N,N-dimethylacrylamide) hydrogels of different morphology," Polymer International, vol. 54, no. 8, pp. 1205-1211, 2005.

[70] Z. Chen, C. Cohen, and F. A. Escobedo, "Monte Carlo simulation of the effect of entanglements on the swelling and deformation behavior of end-linked polymeric networks," Macromolecules, vol. 35, no. 8, pp. 3296-3305, 2002.

[71] P. J. Flory, Principles of Polymeric Chemistry, Cornell University Press, Ithaca, NY, USA, 1953.

[72] J. Chen and Y. Zhao, "Relationship between water absorbency and reaction conditions in aqueous solution polymerization of polyacrylate superabsorbents," Journal of Applied Polymer Science, vol. 75, no. 6, pp. 808-814, 2000.

[73] A. Pourjavadi, A. M. Harzandy, and H. Hosseinzadeh, "Synthesis of novel polysaccharide-based superabsorbent hydtogel via graft coplymerization of acrylic acid onto kappacarragenan in air," European Polymer Journal, vol. 40, pp. 1363-1370, 2004.

[74] I. E. Pacios, M. J. Molina, M. Rosa Gonez-Anton, and I. F. Pierola, "Correlation of swelling and crosslinking density with the composition of the reactiong mixture employed in radical crosslinking copolymerization," Journal of Applied Polymer Science, vol. 103, pp. 263-269, 2007.

[75] S. P. Obukhov, M. Rubinstein, and R. H. Colby, "Network modulus and superelasticity," Macromolecules, vol. 27, no. 12, pp. 3191-3198, 1994.

[76] H. Furukawa, "Effect of varying preparing-concentration on the equilibrium swelling of polyacrylamide gels," Journal of Molecular Structure, vol. 554, no. 1, pp. 11-19, 2000.

[77] P. G. De Gennes, Scaling Concepts in Polymer Ohysics, Cornell University Press, Ithaca, NY, USA, 1979. 

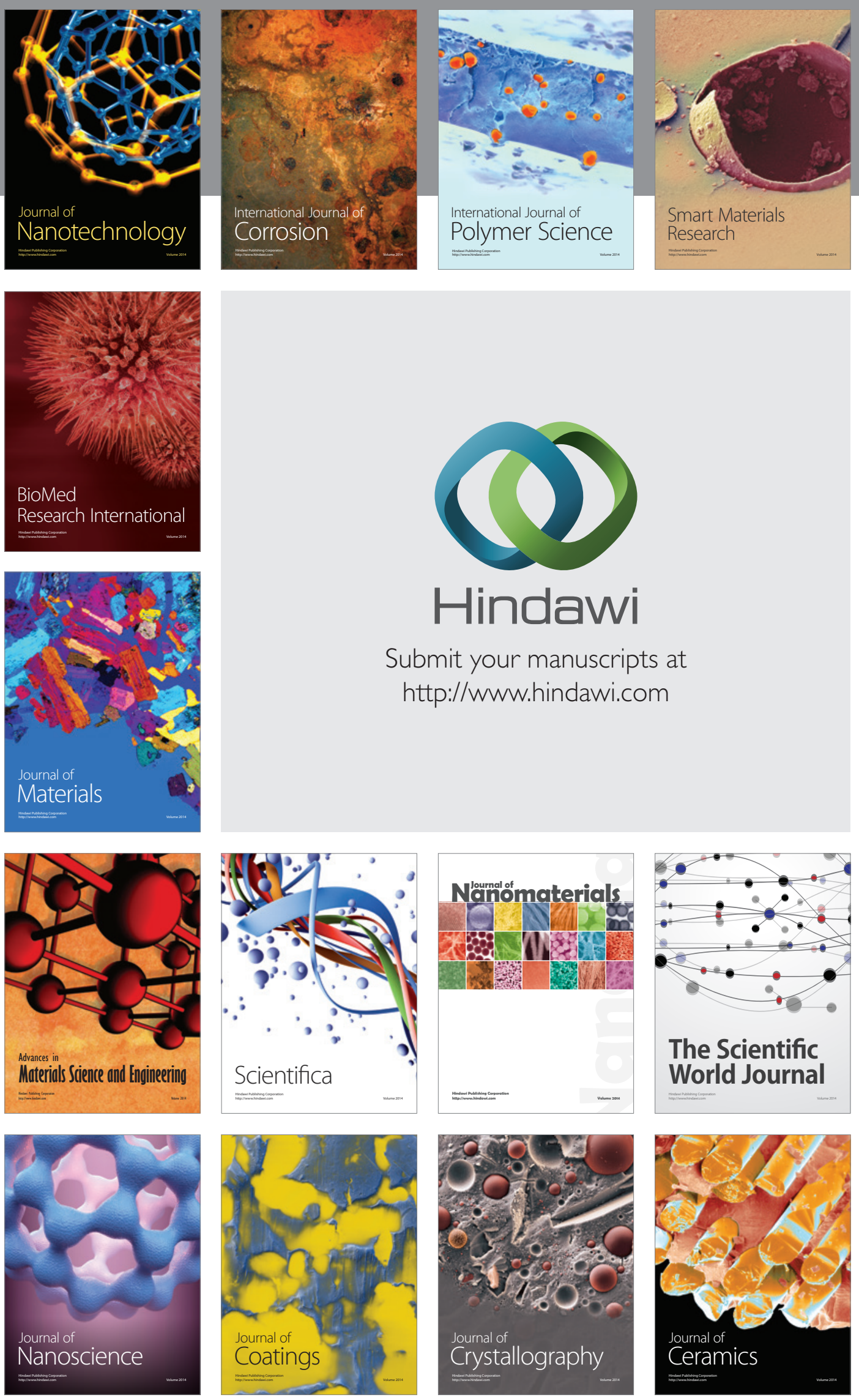

The Scientific World Journal

Submit your manuscripts at

http://www.hindawi.com

\section{World Journal}

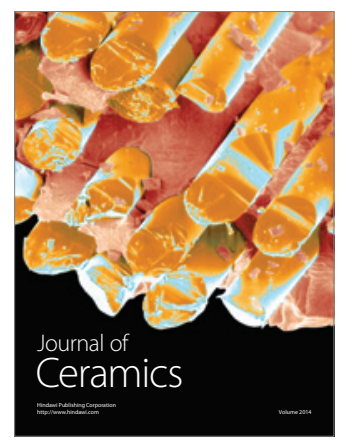

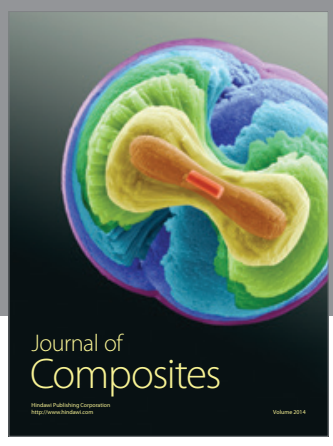
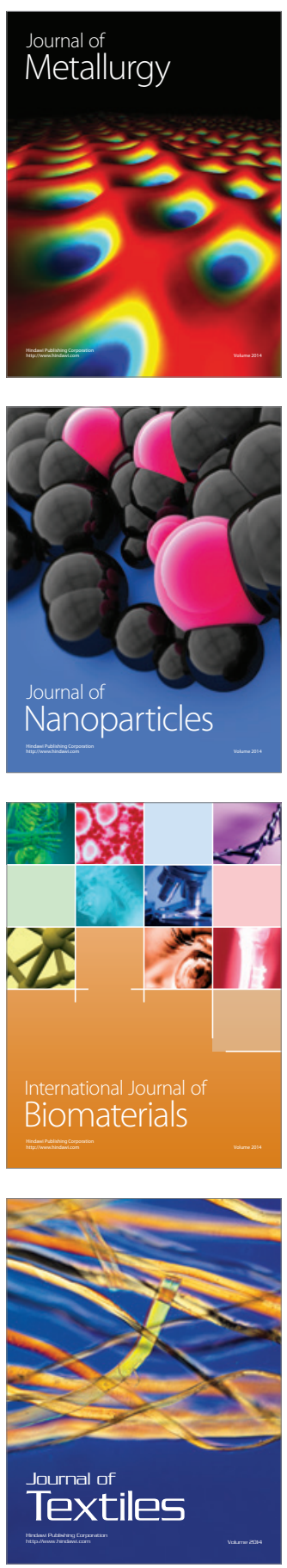